\section{AB1101 THE PERFORMANCE OF COMPUTED TOMOGRAPHY FOR ASSESSING SACROILIITIS IN EARLY SPONDYLOARTHRITIS: WHICH STRUCTURAL LESIONS ARE MOST CONTRIBUTIVE TO THE DIAGNOSIS?}

D. Ben Nessib ${ }^{1}$, H. Riahi' ${ }^{2}$, D. Kaffel ${ }^{1}$, E. Labbene ${ }^{2}$, K. Maatallah ${ }^{1}$, M. Bouaziz ${ }^{2}$, M. M. Kchir ${ }^{1}$, W. Hamdi ${ }^{1}$, F. Ladeb ${ }^{2} .{ }^{1}$ Kassab Institute of Orthopedics, Rheumatology, Mannouba, Tunisia; ${ }^{2}$ Kassab Institute of Orthopedics, Radiology, Mannouba, Tunisia

Background: Computed tomography (CT) of sacroiliac joints (SIJ) is usually considered as a third-line modality in the diagnosis of spondyloarthritis $(\mathrm{SpA})$, as it shows only structural lesions. According to 2015 EULAR recommendations, CT may be helpful if conventional radiograph is inconclusive and MRI cannot be performed [1]. However, its contribution for the early assessment of sacroiliitis is still little-studied.

Objectives: The purpose of this study was to assess the performance of CT scan for detecting sacroilitis and the contribution of the different structural lesions to the early diagnosis of SpA.

Methods: This cross-sectional prospective monocentric study included consecutive patients, aged over 16, consulting for symptoms suggestive of SpA between February 2014 and 2017. Patients with a pelvic radiograph showing a confirmed sacroiliitis (making CT unnecessary to confirm the diagnostic) were not included. Eligible patients underwent $\mathrm{CT}$ of SIJ and the images were reviewed by 2 experimented musculoskeletal radiologists blinded to clinical findings. Then, 2 experienced rheumatologists analyzed clinical, biological and radiological data and classified patients into 2 groups: confirmed non-radiographic spondyloarthritis (nr-SpA) or no SpA. This classification was considered as the gold standard of this study.

Results: A total of 60 patients, 45 women and 15 men, were included in this study. Forty-six patients were assessed as confirmed nr-SpA (76.6\%) and 14 patients as no SpA (23.4\%). Mean age at the diagnosis was $39.5 \pm 10.8$ years [17-59], and the disease duration from first symptoms was $48.6 \pm 40$ months [6.6-180]. Chronic back pain met the Calin criteria in 37 patients $(61.7 \%)$, the Berlin criteria in 46 patients $(76.7 \%)$ and the ASAS criteria in 32 patients $(53.3 \%)$ Among the patients diagnosed as confirmed $\mathrm{SpA}, 71.7 \%$ were determined to have sacroiliitis at CT. As shown by the following table, the most sensitive lesion was subchondral bone sclerosis and the most specific one was new bone formation at entheses:

Table

\begin{tabular}{|c|c|c|c|c|c|c|c|}
\hline & $\begin{array}{l}\text { Confirmed } \\
\text { SpA }\end{array}$ & No SpA & $P$ & $\begin{array}{l}\mathrm{Se} \\
(\%)\end{array}$ & $\begin{array}{l}\mathrm{Sp} \\
(\%)\end{array}$ & $\begin{array}{l}\text { PPV } \\
(\%)\end{array}$ & $\begin{array}{l}\text { NPV } \\
(\%)\end{array}$ \\
\hline Interruption of subchondral bone & $67.4 \%$ & $28.6 \%$ & $0.01(\mathrm{~S})$ & 67.4 & 71.4 & 88.6 & 40 \\
\hline subchondral bone erosions & $65.2 \%$ & $35.7 \%$ & $0.05(\mathrm{~S})$ & 65.2 & 64.3 & 85.7 & 36 \\
\hline Subchondral bone sclerosis & $78.3 \%$ & $28.6 \%$ & $0.001(\mathrm{~S})$ & 78.3 & 71.4 & 90 & 50 \\
\hline new bone formation at entheses & $10.9 \%$ & $7.14 \%$ & 0.68 (NS) & 10.9 & 92.9 & 83.3 & 24 \\
\hline CT conclusion: sacroiliitis & $71.7 \%$ & $28.6 \%$ & $0.04(\mathrm{~S})$ & 71.7 & 71.4 & 89.2 & \\
\hline
\end{tabular}

CT: computed tomography, SpA: Spondyloarthritis, Se: Sensitivity, Sp: Specificity, PPV: Positive Predictive Value, NPV: Negative Predictive Value

Conclusion: The relatively limited place of SIJ CT can be explained by the lack of investigations evaluating its real contribution in detecting sacroiliitis In this study, we found that the main SI structural lesions were significantly associated to the final diagnosis of SpA with a sensitivity up to $78.3 \%$ and a specificity up to $92.9 \%$. The main limitation of this technique remains the large radiation dose delivered to the gonads, especially with the commonly used axial position for CT. However, recent studies found that oblique coronal CT imaging seems to be a very promising technique, since it allows visualization of the subtle radiologic signs of sacroiliitis while delivering less radiation dose [2].

References:

[1] Mandl P, Navarro-Compán V, Terslev L, et al (2015) EULAR recommendations for the use of imaging in the diagnosis and management of spondyloarthritis in clinical practice. Ann Rheum Dis 74:1327-1339. https://doi. org/10.1136/annrheumdis-2014-206971

[2] Li SG, Liu X, Zhou H, Zhang Q (2018) Interrater reliability and radiation dosage of oblique coronal computed tomography. Br J Radiol 91:6. https://doi. org/10.1259/bjr.20150700

Disclosure of Interests: None declared
DOI: 10.1136/annrheumdis-2020-eular.5283

\begin{tabular}{l|l}
\hline AB1102 & COLOR DOPPLER ULTRASOUND OF SACROILIAC \\
JOINTS COMPARED WITH MAGNETIC \\
RESONANCE IMAGING IN NON RADIOGRAPHIC \\
SPONDYLOARTHRITIS
\end{tabular}

M. Bouaziz ${ }^{1}$, D. Ben Nessib ${ }^{2}$, H. Riahi ${ }^{1}$, K. Maatallah ${ }^{2}$, E. Labbene ${ }^{1}$, H. Ferjani ${ }^{2}$, M. M. Kchir ${ }^{2}$, W. Hamdi ${ }^{2}$, F. Ladeb ${ }^{1} .{ }^{1}$ Kassab Institute of Orthopedics, Radiology, Mannouba, Tunisia; ${ }^{2}$ Kassab Institute of Orthopedics, Rheumatology, Mannouba, Tunisia

Background: Magnetic resonance imaging (MRI) of sacroiliac joints (SIJ) can assess early inflammatory changes, thus allowing an early diagnosis of spondyloarthritis $(\mathrm{SpA})$. However, its use in clinical practice may be limited by its cost, its duration and its limited availability. In this sense, ultrasound (US) has been suggested as a feasible and easy-to-apply alternative.

Objectives: The objective of this study was to evaluate the validity of Color Doppler Ultrasound (CDUS) in early assessment of sacroiliitis, compared to MRI findings as the gold standard.

Methods: A cross-sectional prospective monocentric study included patients attending the rheumatology department with suggestive signs of SpA between February 2014 and February 2017. Patients with pelvic radiography showing a confirmed sacroiliitis (grade 3 or 4 ) were not included. Eligible patients underwent US and MRI of SIJ. US examinations were performed by an experimented musculoskeletal radiologist blinded to MRI results. Vas cularization within the SIJs was explored by the presence of a CDUS. When an artery was found, the resistive index (RI) was measured. The values of the $\mathrm{RI}$ ranged between 0 and 1. Doppler of each SIJ was considered as positive when $\mathrm{RI}$ was $<0.75$

Results: Forty-three patients were included: 10 men and 33 women, with an average age at inclusion of $40.2 \pm 11.1$ years [17-59]. The mean duration of symptoms was $46 \pm 37.5$ months [6.6-180]. A personal history of uveitis was noted in 3 patients and of chronic diarrhea in 3 patients. Morning stiffness was noted in $72 \%(n=31)$ of patients. Good response to nonsteroidal anti-inflammatory drugs (NSAIDs) and to physical activity were respectively reported by $41.8 \%(n=18)$ and $58 \%(n=25)$ of patients. Sacroiliac compression test, distraction provocative test, sacral thrust test, Gaenslen's test, Faber's test (Patrick) and Mennel's test were respectively positive in $39.5 \%, 32.5 \%, 48.8 \%, 23.2 \%$, $32.5 \%$, and $51.2 \%$ of the patients. Twenty-seven per cent of the patients were HLA-B27+. The MRI showed a confirmed sacroiliitis in 14 patients. Doppler signal was detected in 44 SIJ of 25 patients, of whom 14 SIJ of 8 patients showed bone marrow edema at MRI $(p=0.054)$. At the joint level, considering MRI-proven sacroiliitis as the diagnostic standard, CDUS had a sensitivity of $70 \%$, a specificity of $54.5 \%$, a positive predictive value of $31.8 \%$, and a negative predictive value of $85.7 \%$. The spectral Doppler RI, averagely estimated at $0.74 \pm 0.12$ [0.48-0.87], was not associated with the presence of sacroiliitis on MRI ( $p=0.747)$.

Conclusion: US, an imaging technique increasingly used in the assessment of musculoskeletal diseases, has been suggested to detect active sacroiliitis [1 2]. Our study revealed that in early SpA, CDUS may be useful to assess active inflammatory changes of SIJ since it had a sensitivity of $70 \%$, despite a relatively reduced specificity. However, RI values, which are expected to be low in patients with active inflammation [3], were unrelated to the presence of sacroiliitis. Future studies on larger numbers of patients might be conducted to complete previous data.

\section{References:}

[1] Mohammadi A, Ghasemi-rad M, Aghdashi M, et al (2013) Evaluation of disease activity in ankylosing spondylitis; diagnostic value of color Doppler ultrasonography. Skeletal Radiol 42:219-224. https://doi.org/10.1007/ s00256-012-1412-7

[2] $\mathrm{Hu}$ Z, Xu M, Wang Q, et al (2015) Colour Doppler ultrasonography can be used to detect the changes of sacroiliitis and peripheral enthesitis in patients with ankylosing spondylitis during adalimumab treatment. Clin Exp Rheumatol 33:844-850

[3] Arslan H, Sakarya ME, Adak B, et al (1999) Duplex and color Doppler sonographic findings in active sacroiliitis. AJR Am J Roentgenol 173:677-680. https://doi.org/10.2214/ajr.173.3.10470902

Disclosure of Interests: None declared

DOI: 10.1136/annrheumdis-2020-eular.4954 